\title{
An asymmetric pericyclic cascade approach to 3-alkyl-3-aryloxindoles; generality, applications and mechanistic investigations
}

Received ooth January 2012, Accepted ooth January 2012

DOI: 10.1039/xoxxo0000x

www.rsc.org/
Edward Richmond, ${ }^{a}$ Kenneth B. Ling, ${ }^{a}$ Nicolas Duguet, ${ }^{a}$ Lois B. Manton, ${ }^{a}$ Nihan Çelebi-Ölçüm, ${ }^{b, c}$ Yu-hong Lam, ${ }^{b}$ Sezen Alsancak, ${ }^{c}$ Alexandra M. Z. Slawin, ${ }^{a}$ K. N. Houk ${ }^{* b}$ and Andrew D. Smith ${ }^{* a}$

The reaction of L-serine derived $\mathrm{N}$-arylnitrones with alkylarylketenes generates asymmetric 3alkyl-3-aryloxindoles in good to excellent yields (up to 93\%) and excellent enantioselectivity (up to $98 \%$ ee) via a pericyclic cascade process. The optimization, scope and applications of this transformation are reported, alongside further synthetic and computational investigations. The preparation of the enantiomer of a Roche anti-cancer agent (RO4999200) 1 (96\% ee) in three steps demonstrates the potential utility of this methodology.

\section{Introduction}

Cascade reactions are highly desirable owing to the ability to perform multiple sequential transformations without the necessity for additional manipulation or introduction of further reagents. Such approaches allow significant molecular complexity to be rapidly assembled, provided each subsequent transformation in the cascade unmasks a desirable, reactive functionality. ${ }^{1}$ Pericyclic cascades are particularly attractive given their predictable regio- and stereocontrol, ${ }^{2}$ coupled with the potential to readily generate multiple carbon-carbon bonds. Significant attention has focused on the expansion of this field toward both carbocyclic and heterocyclic frameworks. ${ }^{3}$ The 3,3-disubstituted oxindole scaffold is an appealing target given the prevalence of naturally occurring species ${ }^{4}$ and medicinal agents containing this core structure. ${ }^{5}$ Notably, alkaloids $\mathbf{2}^{6}$ and $3^{7}$ have both been prepared from 3,3-disubstituted oxindole precursors (Fig 1).

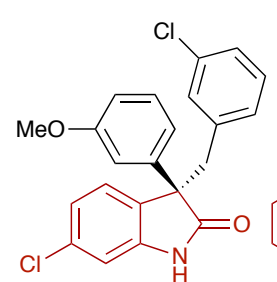

1, p53 inhibitor (Roche)

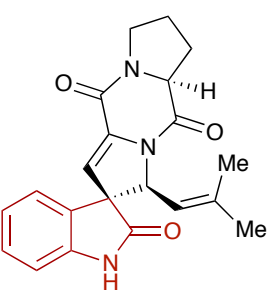

2, spirotryprostatin B

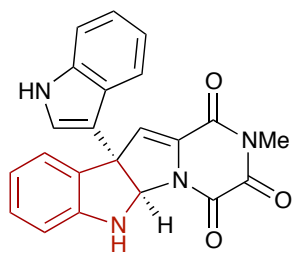

3, gliocladin C
Fig. 1. Oxindole medicinal agent $\mathbf{1}$ and natural products 2 and $\mathbf{3}$ accessed synthetically from 3,3-disubstituted oxindoles.

As a consequence of their wide-ranging biological properties, and given the synthetic community's interest in developing novel approaches toward the preparation of molecules with quaternary stereocentres, ${ }^{8}$ 3,3-disubstituted oxindoles have emerged as ideal frameworks on which to develop new asymmetric methodologies. ${ }^{9}$ Typically, such approaches employ anilides, isatins or suitably substituted oxindole derivatives as starting materials (Fig 2), although numerous other standalone approaches have also been developed. ${ }^{9 b, c, 10-12}$ Asymmetric intramolecular anilide cyclizations ${ }^{13}$ or Heck reactions ${ }^{14}$ typically employ a palladium catalyst in combination with chiral ligands (a), and have found wide application in synthesis. ${ }^{15}$ In similar systems, direct coupling approaches, without the necessity for pre-activation have been developed. ${ }^{16}$ However, these approaches have yet to be rendered enantioselective. $O$-to- $C$ transfer reactions (b) have also been used to great effect including Trost's asymmetric allylic alkylation methodology, ${ }^{17}$ and Lewis base-catalyzed $O$ to- $C$ carboxyl transfer reactions. ${ }^{18}$ A plethora of catalytic methodologies has been developed over the past decade employing isatins (c) as starting materials, ${ }^{19}$ giving access to 3 substituted-3-hydroxyoxindoles that serve as convenient synthetic intermediates. ${ }^{20}$ Latterly, both stoichiometric and catalytic asymmetric alkylation approaches (d) have been reported to access 3,3-disubstituted oxindole species. ${ }^{21}$ This manuscript details the asymmetric cycloaddition cascade reaction between nitrones and ketenes (e), allowing direct access to the unprotected 3,3-disubstituted oxindole motif. This method contrasts the commonly employed approaches that require protection of the amide functionality, thereby generating $N$-protected oxindoles. 


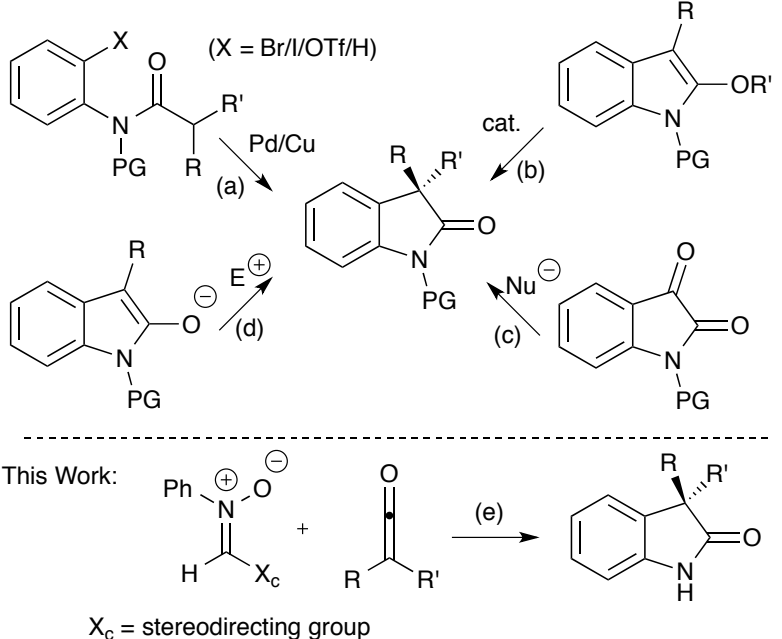

Fig. 2. Typical approaches toward asymmetric 3,3-disubstituted oxindoles.

\section{Previous Studies and Mechanism}

The hetero-Claisen approach to oxindoles using $\mathrm{N}$ phenylnitrones and diphenylketene was first reported by Staudinger ${ }^{22}$ and subsequently investigated by Lippman ${ }^{23}$ and Taylor. ${ }^{24}$ Despite its synthetic potential, an asymmetric variant of this process was overlooked until we developed an asymmetric route to 3,3-disubstituted oxindoles (up to $90 \%$ ee) using Garner's aldehyde derived $N$-aryl nitrones and disubstituted ketenes. ${ }^{25}$ Subsequent studies extended this methodology to the construction of asymmetric 3,3spirocarbocyclic oxindoles, ${ }^{26}$ and computational studies led to a revised mechanistic rationale for these processes. ${ }^{27}$ The mechanistic pathway is consistent with a $3+2$ cycloaddition across the ketene $\mathrm{C}=\mathrm{O}$ bond, with preferential anti-addition with respect to the aryl portion of the ketene. Facial selectivity in this cycloaddition is controlled by the preferred arrangement of large and electronegative allylic groups, and 1,3-allylic strain $^{28}$ within the enantiopure nitrone chiral auxiliary 4 , generating a stereodefined five-membered intermediate $\mathbf{5}$. Subsequent [3,3]-sigmatropic rearrangement yields 6 that undergoes rearomatization and tautomerization to imino acid 7. Each of these steps was established by computational studies of the reaction transition states. ${ }^{27}$ Acidic hydrolysis and concomitant cyclization generates the oxindole $\mathbf{8}$ with excellent enantiocontrol and regenerates chiral aldehyde 9 (Fig 3). ${ }^{29}$

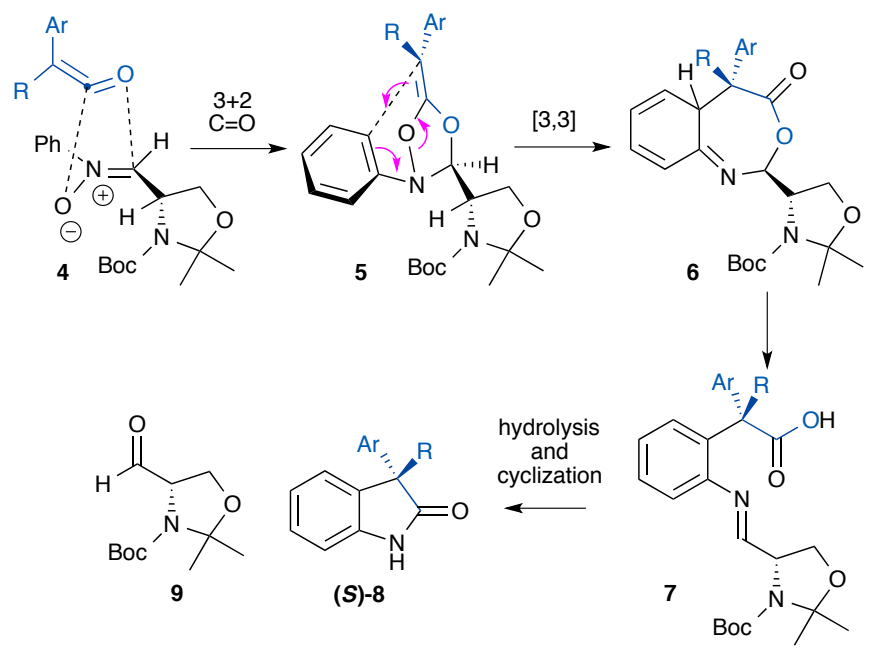

Fig. 3. Proposed mechanism.

The ability of this methodology to generate highly substituted quaternary stereocentres at the oxindole $\mathrm{C}(3)$ position with excellent enantiocontrol (up to $90 \%$ ee), coupled with the inexpensive nature of the starting materials, warranted further development of this reaction manifold. To this end, this manuscript describes our studies devoted to optimization of the levels of enantioselectivity in this transformation, alongside computational and experimental mechanistic studies of this process. The full scope and limitations of the optimized process are delineated, as well as its application to a target Roche anticancer agent (RO4999200).

\section{Results and Discussion}

\section{Stereodirecting Group Optimization}

To explore the necessary structural requirements for generating high enantiocontrol in this reaction manifold, a range of enantiopure $N$-aryl nitrones 11-16 was synthesized from readily available chiral starting materials. These nitrones were then evaluated in the pericyclic cascade process with ethylphenylketene (Fig 4). ${ }^{30}$ Initially, Naproxen-derived nitrone 11 was synthesized and evaluated, generating oxindole $\mathbf{1 0}$ in a poor $27 \%$ ee. Mannitol-derived nitrone $\mathbf{1 2}$ proved more successful, providing oxindole $\mathbf{1 0}$ in $78 \%$ yield and $70 \%$ ee after treatment with ethylphenylketene. An $\alpha$-oxygenated series of nitrones 13-16, derived from $(S)$-ethyl lactate, was also synthesized and tested. These nitrones proved difficult to isolate and were consequently prepared and evaluated in situ. ${ }^{31}$ A general trend of increasing enantioselectivity with increasing substituent size was observed, with $O$-TIPS-substituted nitrone $\mathbf{1 5}$ delivering $\mathbf{1 0}$ in $80 \%$ ee. 


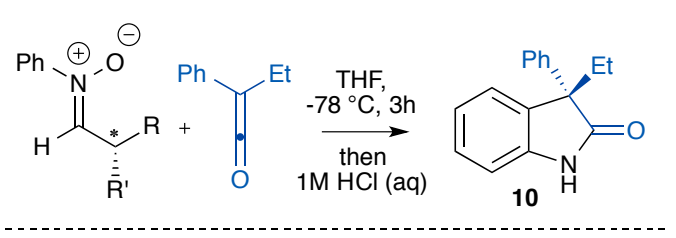

Nitrones evaluated:<smiles>COc1ccc2cc(C([C@@H](C)/C=[N+](/[O-])c3ccccc3)[N+](=O)[O-])ccc2c1</smiles>

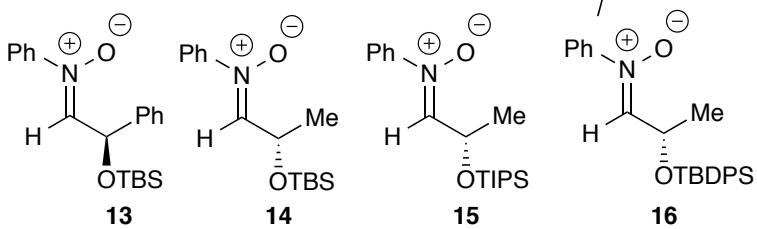

13

14

15

16

\begin{tabular}{cccc}
\hline Entry & Nitrone & $\begin{array}{c}\text { Oxindole } \\
\text { Yield (\%) }\end{array}$ & $\begin{array}{c}\text { Oxindole } \\
\text { ee (\%) }\end{array}$ \\
\hline 1 & $\mathbf{1 1}$ & 43 & $27($ ent $)$ \\
2 & $\mathbf{1 2}$ & 78 & $70($ ent $)$ \\
3 & $\mathbf{1 3}$ & 25 & $<5$ \\
4 & $\mathbf{1 4}$ & 32 & 60 \\
5 & $\mathbf{1 5}$ & 70 & 80 \\
6 & $\mathbf{1 6}$ & 38 & 32
\end{tabular}

Fig. 4. Variation of the chiral nitrone. ${ }^{a}$ Isolated yield of oxindole 10 after purification by column chromatography. ${ }^{\text {b }}$ Determined by chiral HPLC analysis.

Subsequent studies prepared and evaluated a series of chiral nitrones bearing a protected nitrogen atom at the $\alpha$-position. The acyclic, $\alpha$-dibenzylamino nitrone 17 provided the oxindole in $70 \%$ ee, but in poor yield. The $N$-Boc nitrone 4 , derived from Garner's aldehyde, gave oxindole 10 in good yield and $84 \%$ ee. This prompted us to evaluate a series of structural analogues of 4 in which the $N$-substituent is varied (Fig 5). Upon treatment with ethylphenylketene, the $N$-benzyl nitrone $\mathbf{1 8}$ gave the desired oxindole with poor enantiocontrol, suggesting that structural rigidity or restricted rotation at this position may be crucial to engendering high levels of enantioselectivity. As a consequence, a sulfonamide substituent was investigated. With $\mathrm{N}$-tosyl nitrone 19, the oxindole was obtained in good yield and excellent enantiocontrol ( $75 \%$ yield, $91 \%$ ee). Increasing the size of the sulfonamide group was found to improve the enantioselectivity, as the use of $N$-TIPBS $(2,4,6-$ triisopropylbenzenesulfonyl) nitrone $\mathbf{2 0}$ furnished oxindole $\mathbf{1 0}$ in $86 \%$ yield and $96 \%$ ee. A single-crystal X-ray structure of 20 was obtained, and gives an excellent representation as to the steric impact of this TIPBS residue. ${ }^{32}$ Further studies allowed for preparation of $\mathbf{2 0}$ on gram scale (see SI for details).

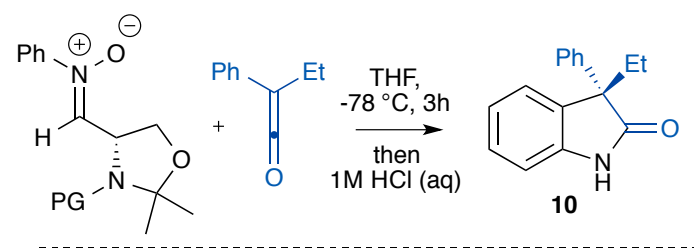

$$
\text { Nitrones evaluated: }
$$<smiles>CC1OC[C@H](/C=[N+](\[O-])c2ccccc2)N1C(=O)OCc1ccccc1</smiles><smiles>CC1(C)OC[C@@H](/C=[N+](\[O-])c2ccccc2)N1Br</smiles>

17

4<smiles>CCC/C=[N+](/[O-])c1ccccc1</smiles><smiles>Cc1ccc(S(=O)(=O)N2CCOC2(C)C)cc1</smiles><smiles>CCC/C=[N+](/[O-])c1ccccc1</smiles>
18

\begin{tabular}{cccc}
\hline Entry & Nitrone & $\begin{array}{c}\text { Oxindole } \\
\text { Yield (\%) }\end{array}$ & $\begin{array}{c}\text { Oxindole } \\
\text { ee (\%) }^{\mathbf{b}}\end{array}$ \\
\hline 1 & $\mathbf{1 7}$ & 21 & 70 \\
2 & $\mathbf{4}$ & 83 & 84 \\
3 & $\mathbf{1 8}$ & 60 & 20 \\
4 & $\mathbf{1 9}$ & 75 & 91 \\
5 & $\mathbf{2 0}$ & 86 & 96
\end{tabular}

Fig. 5. Optimization of stereodirecting groups on the nitrone. ${ }^{a}$ Isolated yield of oxindole $\mathbf{1 0}$ after purification by column chromatography. ${ }^{\text {b }}$ Determined by chiral HPLC analysis.

\section{Computational Studies - Role of the $\mathrm{N}$-Substituent in Determining Enantioselectivity}

In order to understand the origin of the effect of the size of the $N$-substituent on the enantioselectivity of the reaction, the competing stereoisomeric transition structures (TSs) for nitrones 4, ent-12, and 20 were located using Gaussian $09^{33}$ at the M06-2X/6-311+G(d,p)//B3LYP/6-31G(d) level. In the proposed mechanism, the stereochemical outcome of the reaction is determined at the $3+2$ cycloaddition step of the pericyclic cascade simultaneously by the facial selectivity of the nitrone and the direction of attack on the ketene. ${ }^{27}$ Our previous calculations have shown that the approach of ketene from the $R e$ face of nitrone is strongly disfavored as it places the ring methylene group at the sterically more demanding inside position. Indeed, nitrones $\mathbf{4}$, ent-12 and $\mathbf{2 0}$ all displayed significantly high $\pi$-facial selectivities with the $S i$ face attack contributing more than $97 \%$ to the diastereomeric cycloadduct distribution (see SI), and the competing stereodetermining factor was the orientation of the unsymmetrically substituted ketene at the TS (Fig 6).

We initially considered the 2,2-dimethyl-1,3-dioxolanyl auxiliary (Fig 6, $\mathrm{X}=\mathrm{O}$ ) to study the stereoinduction in the absence of steric interactions from the protecting group. The 
calculations predict $1.4 \mathrm{kcal} / \mathrm{mol}$ difference in free energy between TSE-O and TSZ-O favoring the trans addition with

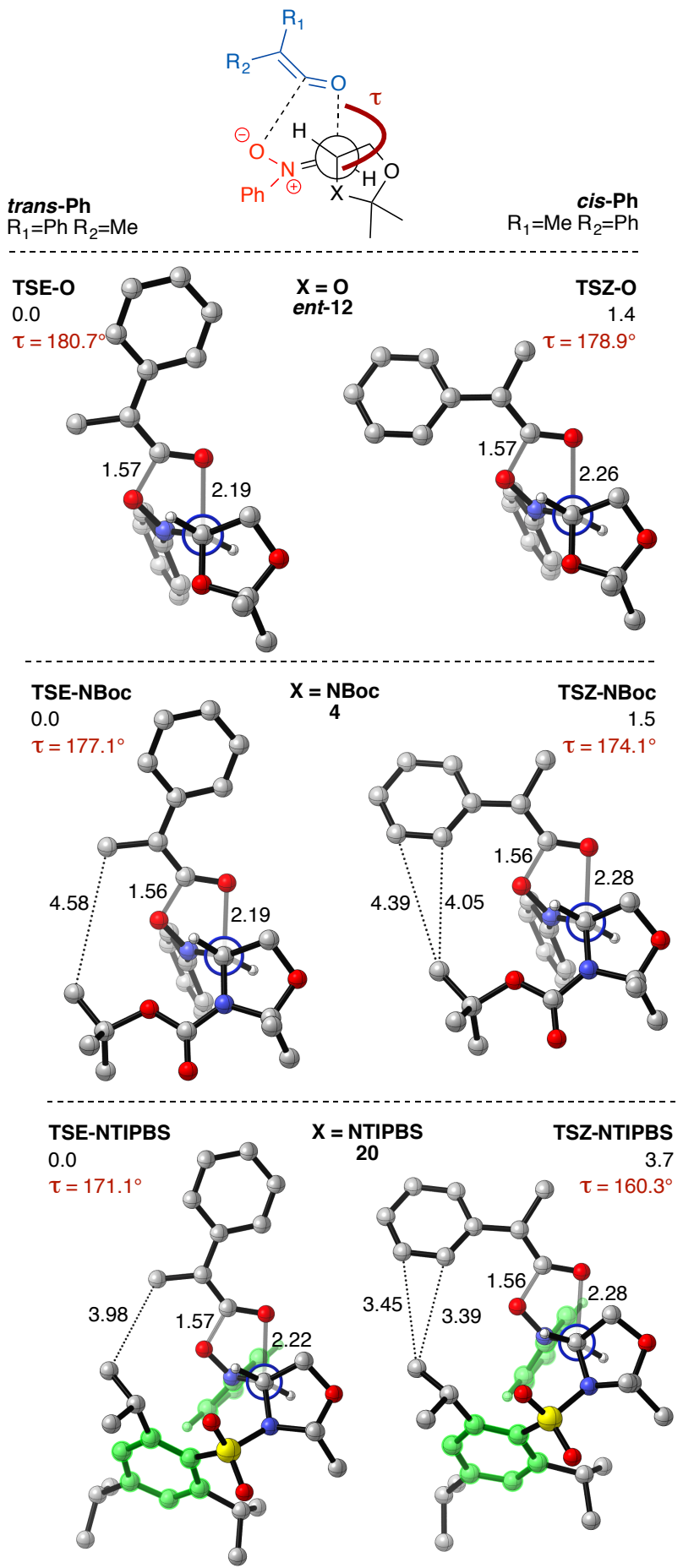

Fig. 6. Relative Gibbs free energies (in $\mathrm{kcal} / \mathrm{mol}$ ) of stereoselectivity-determining $3+2$ cycloaddition transition structures for nitrones $\mathbf{4}$, ent-12 and $\mathbf{2 0}$, calculated with M06-2X/6-311+G(d,p)(THF)//B3LYP/6-31G(d). The hydrogen atoms, except those around the Newman projections, are omitted for clarity.

respect to the phenyl portion of the ketene. The cycloaddition occurs in the plane of ketene substituents, and the observed trans-phenyl selectivity can be explained by the attack of nitrone from the least hindered side in the plane of ketene. Steric effects of ketene substituents for nucleophilic additions at the ketene LUMO in the plane of substituents are well documented, and are proposed to be responsible for high levels of $E / Z$ selectivities obtained in the reactions of unsymmetrically substituted ketenes with carbon and oxygen nucleophiles. ${ }^{34,35}$

The inclusion of $N$-protected chiral auxiliaries leads to an increase in the $E / Z$ selectivity by introducing a higher degree of steric hindrance at the transition structures with the $\mathrm{Ph}$ group cis (Fig 6, $\mathrm{X}=\mathrm{NBoc}$ and NTIPBS). While the additional contribution of $N$-PG to the selectivity is found to be minimal for $N$-Boc nitrone, the steric effects become significant with the increasing size of the protecting group, disfavoring TSENTIPBS compared with TSZ-NTIPBS with an energetic cost that amounts to $4.0 \mathrm{kcal} / \mathrm{mol}$. Steric interactions between the $N$ substituent and the ketene substituents result in substantial deviations in the antiperiplanarity of the $\mathrm{C}-\mathrm{N}$ bond at the TS. The O-C-C-N dihedral angle $(\tau)$ decreases with increasing size of the $N$-substituent and correlates well with the activation energy $\left(R^{2}=0.94\right.$, see $\left.\mathrm{SI}\right)$ suggesting a combination of steric and electronic effects in determining the selectivity of the reaction. A distortion-interaction analysis shows that both distortion and interaction energies favorably contribute to the stabilization of TSE-NTIPBS with respect to TSZ-NTIPBS (see SI). The edge-to-face $\pi$ - $\pi$ interaction displayed in the X-ray structure of nitrone $\mathbf{2 0}$ is well reproduced by the calculations (shown highlighted in Fig 6). ${ }^{36}$

\section{Scope and Limitations}

With $N$-TIPBS nitrone 20 established as the optimum chiral auxiliary for this asymmetric oxindole forming methodology, reactions with a range of alkylarylketenes were undertaken to demonstrate the scope and limitations of this transformation. To provide a direct comparison between the $N$-TIPBS and $N$-Boc nitrone chiral auxiliaries, the reactions with the same series of alkylarylketenes were selected, the results of which are summarized in Fig 7. In all cases, an improvement in ee was observed with $N$-TIPBS nitrone 20, whilst yields remained high and a variety of aryl and alkyl substitution patterns at the C(3)position of the oxindole were successfully incorporated (21-26). 
<smiles>[R]C([Al])=C=O</smiles><smiles>CC1(c2ccccc2)C(=O)Nc2ccccc21</smiles><smiles>CCC1(c2ccccc2)C(=O)Nc2ccccc21</smiles><smiles>O=C1Nc2ccccc2[C@]1(Br)c1ccccc1</smiles>
$(87 \% \text { ee })^{\mathrm{a}}$ 0, $84 \%, 96 \%$ $(81 \% \text { ee })^{\mathrm{a}}$ $(78 \% \text { ee })^{a}$<smiles>CCC1(c2ccc(OC)cc2)C(=O)Nc2ccccc21</smiles>

23, $81 \%, 98 \%$ $(90 \% \text { ee })^{\mathrm{a}}$<smiles>CCC1(c2ccc(C)cc2)C(=O)Nc2ccccc21</smiles><smiles>COc1ccc(C2(C)C(=O)Nc3ccccc32)cc1</smiles>
$\mathrm{N}$

$25,66 \%, 96 \%$ ee $\mathbf{2 6}, 79 \%, 98 \%$ ee $(87 \% \text { ee })^{\mathrm{a}} \quad(80 \% \text { ee })^{\mathrm{a}}$

Fig. 7. Asymmetric oxindole synthesis using nitrone $\mathbf{2 0}{ }^{a}{ }^{a}$ ee values in parentheses represent those obtained using $\mathrm{N}$-Boc nitrone $4 .^{25}$

Using the optimised $N$-TIBPS nitrone 20, an extensive ketene screen showed that numerous alkylarylketenes were well tolerated in this process, yielding the respective oxindoles in good yields although varying ee (Fig 8). ${ }^{37} \beta$-Branching of the alkyl group of the ketene component was well tolerated (27) and reaction with halo-arylketenes yielded oxindoles 28, 29 and 30 in excellent ee. The transformation is also compatible with a $\mathrm{C}(3)$-indolyl substituent, which is common to many natural products, ${ }^{38}$ as oxindoles $\mathbf{3 1}$ and $\mathbf{3 2}$ were furnished in $88 \%$ and $84 \%$ ee, respectively. Ketenes bearing a 2 -substituted phenyl ring (33 and 34) or a 1-naphthyl (35) ring resulted in diminished enantiocontrol, yet these reactions still provided the desired oxindoles in moderate to excellent yields. $\alpha$-Branching of the alkyl substituent resulted in a racemic mixture, as illustrated by the reaction generating oxindole 36. Attempted extension to $\mathrm{C}(3)$-tertiary asymmetric oxindoles using monosubstituted ketenes (generated in situ) allowed the isolation of oxindole 37 in a promising $72 \%$ yield and $50 \%$ ee. However, this species proved configurationally unstable, with slow racemization observed over time. ${ }^{39}$ Oxindole $\mathbf{3 8}$ was generated using a solution of methylketene in $54 \%$ yield, but was racemic.

$$
\text { TIPBS }
$$<smiles>CC[C@]1(c2ccc([18O][18O])cc2)c2ccccc2NC(=O)[C@]1(CC)c1ccc(Cl)cc1</smiles>

27, $89 \%, 84 \%$ ee $\quad \mathbf{2 8}, 88 \%, 96 \%$ ee $\quad \mathbf{2 9}, 44 \%, 94 \%$ ee $\quad \mathbf{3 0}, 40 \%, 94 \%$ ee

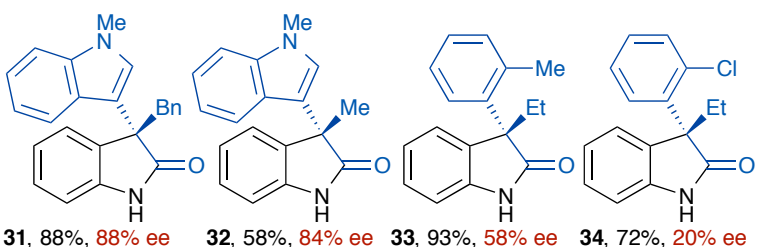

31, $88 \%, 88 \%$ ee $\quad 32,58 \%, 84 \%$ ee $\quad 33,93 \%, 58 \%$ ee $\quad \mathbf{3 4}, 72 \%, 20 \%$ ee<smiles>CC[C@@]1(c2ccccc2)C(=O)Nc2ccccc21</smiles><smiles>CC(C)(C)[C@H]1C(=O)Nc2ccccc21</smiles>

$\mathbf{3 5}, 30 \%, 40 \%$ ee $\quad \mathbf{3 6}, 51 \%,<5 \%$ ee $\quad \mathbf{3 7}, \mathbf{7 2} \%, 50 \%$ ee $\quad \mathbf{3 8}, 54 \%, 0 \%$ ee

Fig. 8. Asymmetric oxindole synthesis; generality.

\section{Regioselectivity}

Attention next turned to substitution of the $\mathrm{N}$-aryl nitrone ring to probe the effect upon regio- and stereoselectivity of this process. 4-Tolyl- and 4-chlorophenyl $\mathrm{N}$-aryl nitrones 39 and $\mathbf{4 0}$ each gave the 5-substituted oxindole as a single regioisomer, in excellent ee and acceptable yields. Similarly, 2-tolyl nitrone $\mathbf{4 3}$ and 2-chlorophenyl nitrone 44 gave 7-substituted oxindoles 45 and 46, respectively, as single regioisomers in good yield although with lower enantioselectivities (Fig 9).

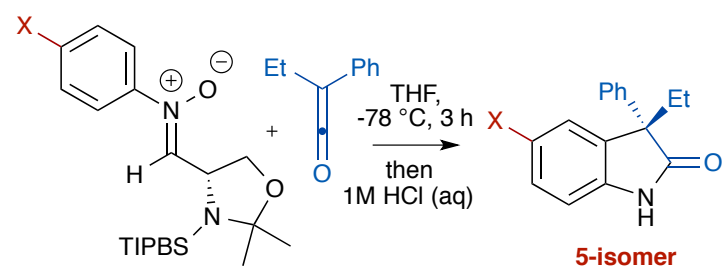

39, $\mathrm{X}=\mathrm{CH}_{3}$

41, $\mathrm{X}=\mathrm{CH}_{3}, 48 \%, 94 \%$ ee $40, \mathrm{X}=\mathrm{Cl}^{3}$ 42, $\mathrm{X}=\mathrm{Cl}, \quad 87 \%, 97 \%$ ee

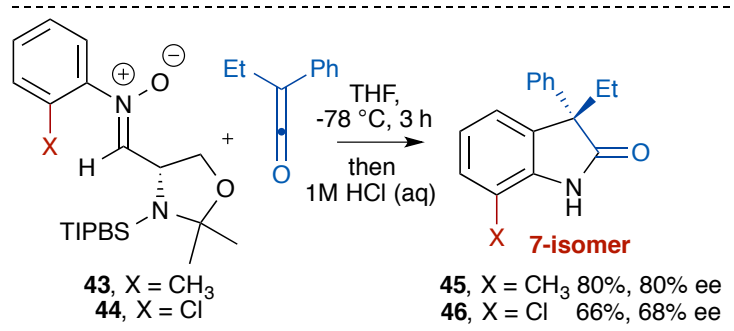

Fig. 9. Asymmetric oxindole synthesis using 4- (39 and 40) or 2-substituted (43 and 44) $\mathrm{N}$-aryl nitrones. 
However, treatment of 3-substituted $\mathrm{N}$-aryl nitrones 47 and 48 with ethylphenylketene gave a 40:60 regioisomeric mixture of the 4- and 6-substituted oxindole isomers respectively, in good yields. Using 3-tolyl nitrone 47, the ee of the inseparable 4- and 6-regioisomers was $91 \%$, while 3-chlorophenyl nitrone 48 gave the separable 4- and 6-chlorooxindoles in 86\% ee (Fig 10).

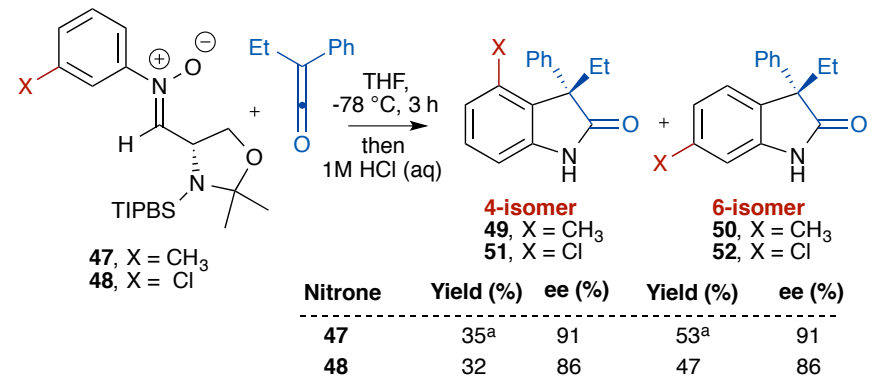

Fig. 10. Regioselectivity trends in the asymmetric oxindole synthesis using 3substituted $\mathrm{N}$-aryl nitrones. ${ }^{\mathrm{a}}$ oxindoles $\mathbf{4 9}$ and $\mathbf{5 0}$ were isolated and analyzed as a mixture of regioisomers in $88 \%$ combined yield: the reported yields refer to $\mathrm{mol} \%$ fraction of total isolated material.

The computed regioselectivity-determining transition structures are shown in Fig 11 for 3-tolyl nitrone 53 and methylphenylketene as the model reactants. According to the proposed pericyclic cascade mechanism, the regioselectivity is dictated by the hetero-Claisen rearrangement step of the $3+2$ cycloadduct. This [3,3]-sigmatropic rearrangement is highly asynchronous since the $\mathrm{C}-\mathrm{C}$ bond is barely formed when the $\mathrm{N}-\mathrm{O}$ bond is being cleaved at the transition state. The perturbation by any substituent at either the 4- or the 6-position is therefore likely to be minimal. Indeed, the free energies of the transition structures for the 4-isomer and the 6-isomer were found to differ only by $0.1 \mathrm{kcal} / \mathrm{mol}$ in favor of the 6 -isomer. This is essentially replicated in experimental investigations with ethylphenylketene (Fig 10) where a minimal preference for the 6-isomer is observed in the case of both chloro- and methyl- substitution.
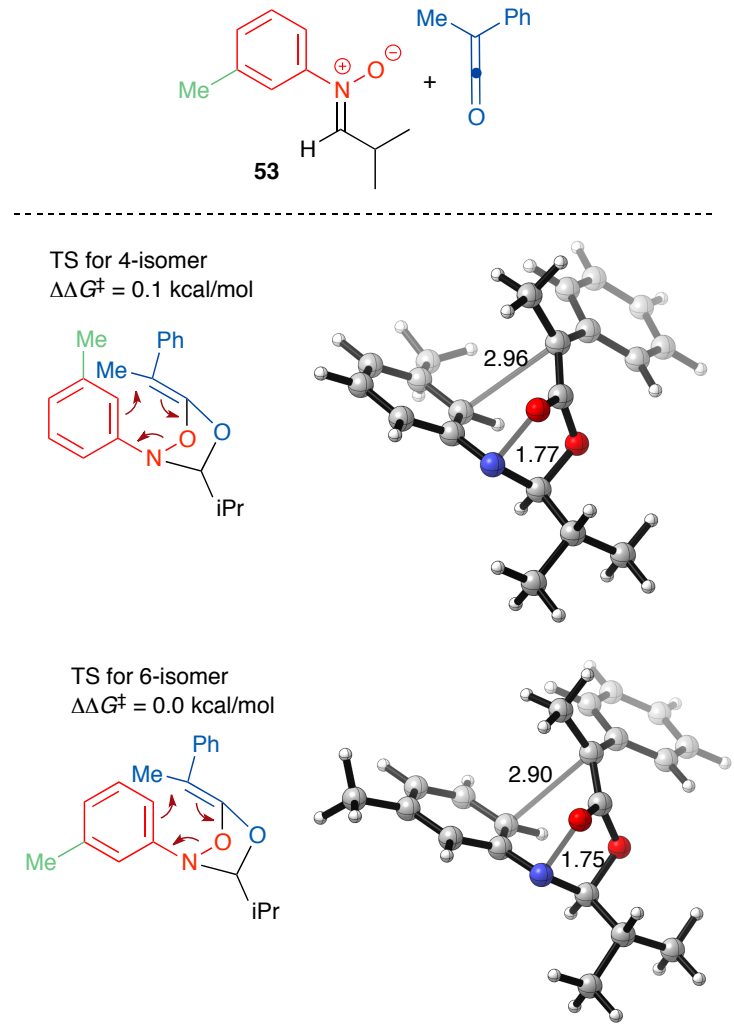

Fig. 11. Regioselectivity-determining transition structures (SCS-MP2/631G(d)(THF)//MP2/6-31G(d)(THF)) involving meta-substituted nitrones.

\section{Mechanistic Validation}

In our recent communication, the computational exploration of the possible reaction pathways for the formation of the key imino acid intermediates in the reactions of $N$-phenyl nitrones with ketenes were evaluated at the M06-2X/6$311+\mathrm{G}(\mathrm{d}, \mathrm{p}) / / \mathrm{B} 3 \mathrm{LYP} / 6-31 \mathrm{G}(\mathrm{d})$ level (Scheme 1). ${ }^{27}$ These studies described a novel 1,3-dipolar cycloaddition and hetero$[3,3]$-rearrangement cascade (Scheme 1, Pathway A) involving a chirality transfer between the highly asynchronous but concerted pericyclic steps. Here, we extend our calculations to the SCS-MP2/6-31G(d)//MP2/6-31G(d) level of theory (Figure $12)$, which provided the best results in an equivalent key $[3,3]-$ sigmatropic rearrangement step of the acid-promoted Fischer indole reaction, where B3LYP optimizations were shown to yield highly asynchronous and dissociative transition states. ${ }^{40}$

In the first step of the pericyclic cascade mechanism, the $3+2$ cycloaddition between nitrone and ketene across the $\mathrm{C}=\mathrm{O}$ bond forms the substituted 1,2,4-dioxazolidine. The $3+2$ cycloaddition transition structure, TS-(3+2), is predicted to be $16.7 \mathrm{kcal} / \mathrm{mol}$ uphill from the starting nitrone and ketene (Fig 12). TS- $(3+2)$ features two forming $\mathrm{C}-\mathrm{O}$ bonds of $1.57 \AA$ and $2.12 \AA$. The geometry and electronic features are in good agreement with the previously described $3+2$ cycloaddition TS obtained using B3LYP. ${ }^{27}$ This cycloaddition step sets the stereochemistry of the 5-membered ring in the cycloadduct involving an unsymmetrically substituted exocyclic alkylidene group. The cycloadduct int-1 is $6.9 \mathrm{kcal} / \mathrm{mol}$ more stable relative to the separated reactants, and smoothly undergoes an 
aromatic hetero-[3,3]-sigmatropic shift via TS-[3,3] with an activation free energy of $2.3 \mathrm{kcal} / \mathrm{mol}$ furnishing the quaternary stereocenter. The following stereospecific hetero-[3,3]rearrangement step transfers the stereochemical information of the cycloadduct to intermediate int-2 installing the desired quaternary stereocenter. TS-[3,3] is early and highly asynchronous; the breaking $\mathrm{N}-\mathrm{O}$ bond is $1.75 \AA$ as the forming $\mathrm{C}-\mathrm{C}$ bond is $2.89 \AA$. The critical distances in the MP2 optimized transition structure are significantly shorter compared to those predicted using B3LYP $\left(d_{\mathrm{C}-\mathrm{C}}(\mathrm{B} 3 \mathrm{LYP})=\right.$ $\left.3.47 \AA, d_{\mathrm{N}-\mathrm{O}}(\mathrm{B} 3 \mathrm{LYP})=1.95 \AA\right)$. The intrinsic reaction coordinate (IRC) path from TS- $[3,3]$ indicates no intermediates, and connected the cycloadduct int-1 to intermediate int-2, which has a relative free energy of $-36.6 \mathrm{kcal} / \mathrm{mol}$ with respect to the separated reactants. Cleavage of the hemiaminal linkage and rearomatization form the aromatic imino acid.

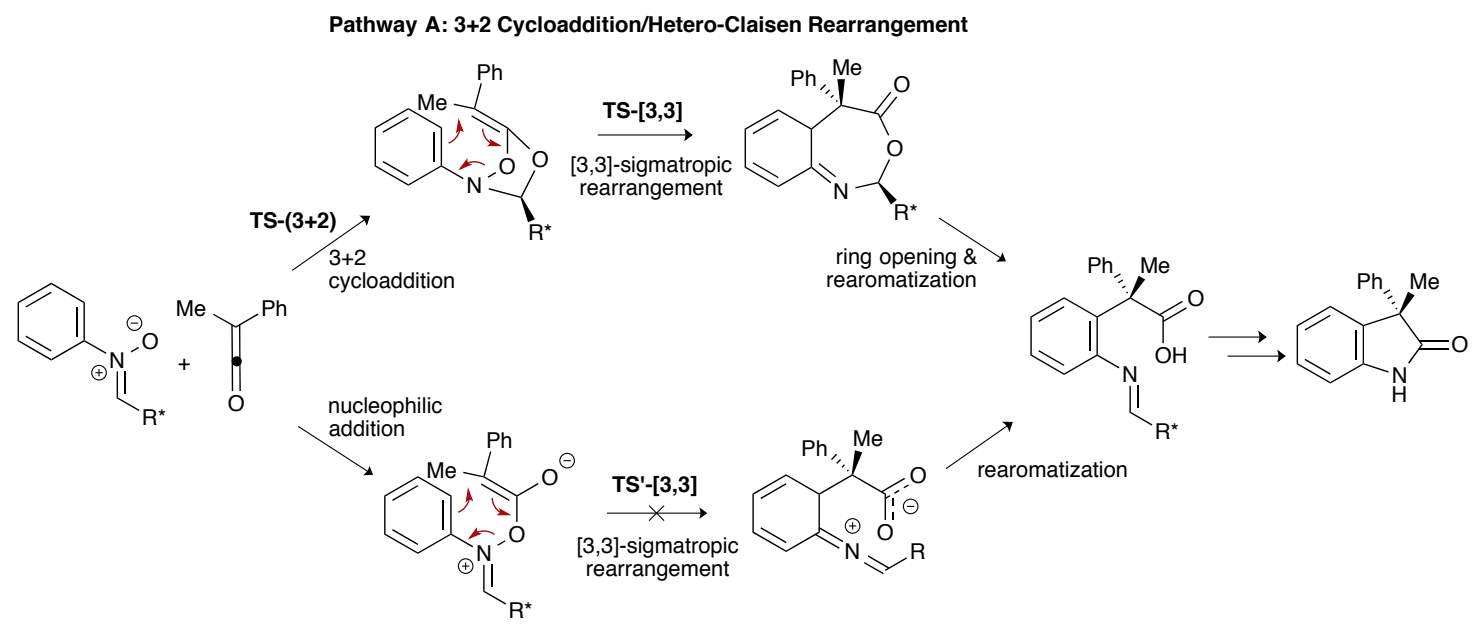

Pathway B: Nucleophilic Addition/Hetero-Claisen Rearrangement

Scheme 1. Mechanistic proposals for the reactions of $\mathrm{N}$-phenylnitrones with disubstituted ketenes.
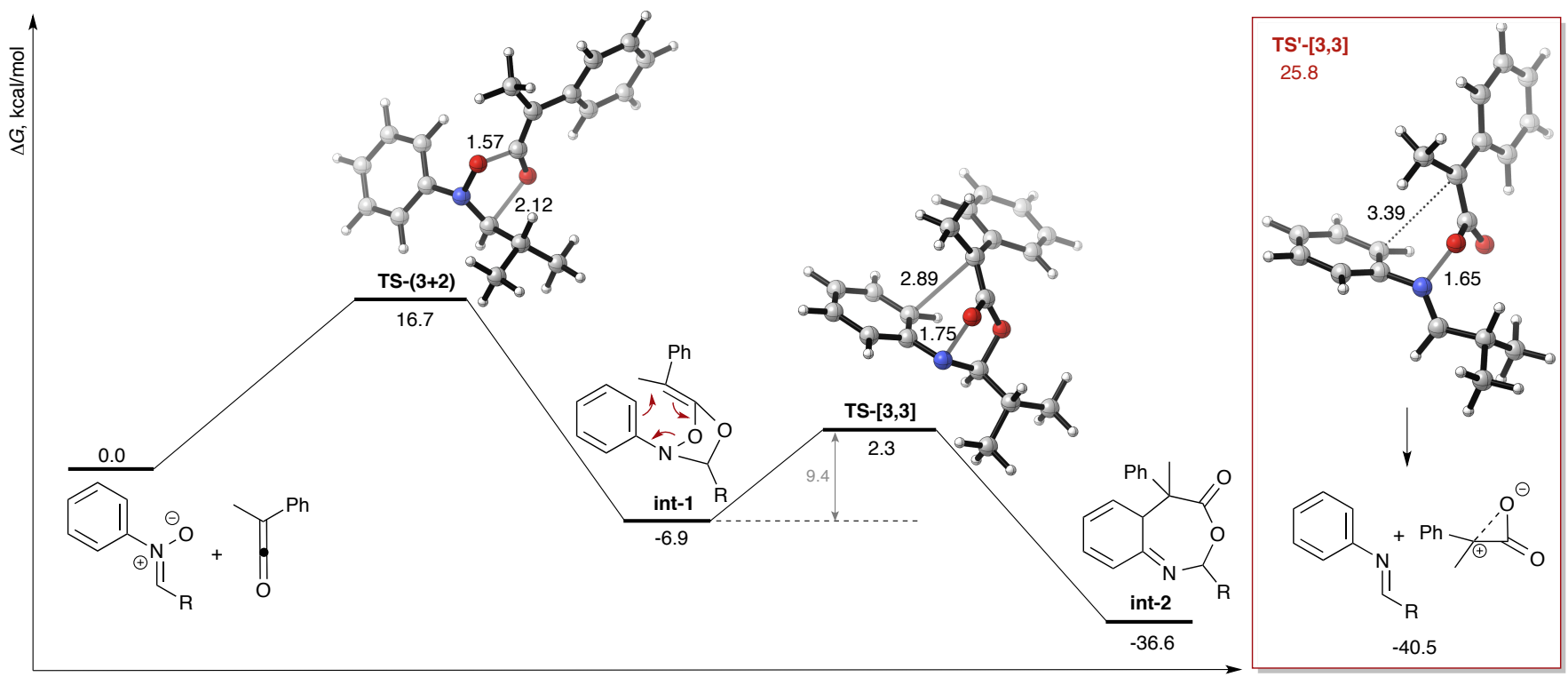

Fig. 12. Pericyclic cascade (Pathway A, Scheme 1 ) and competing heterolytic cleavage pathway (Pathway $B, S c h e m e ~ 1 ; T S '-[3,3])(R=i-P r)$. The relative free energies $(\Delta G, \mathrm{kcal} / \mathrm{mol})$, calculated using SCS-MP2/6-31G $(\mathrm{d}) / / \mathrm{MP} 2 / 6-31 \mathrm{G}(\mathrm{d})$, are given with respect to the separated reactants.

An analogous [3,3]-rearrangement transition structure, TS'$[3,3]$, in a previously proposed nucleophilic addition and hetero-Claisen rearrangement mechanism (Scheme 1, pathway B) led to dissociation rather than rearrangement (red inset, Fig 12). This pathway has a higher free energy of activation $\left(\Delta G^{\star}=\right.$
$25.8 \mathrm{kcal} / \mathrm{mol})$ than the pericyclic cascade $\left(\Delta G^{\ddagger}=16.7\right.$ $\mathrm{kcal} / \mathrm{mol}$ ) and is, therefore, not observed experimentally.

Further mechanistic insight can be gleaned by comparing the sigmatropic rearrangement step in the acid-promoted Fischer indole reaction, the originally proposed, nucleophilic 
addition/hetereo-Claisen rearrangement pathway (Pathway B, Scheme 1), and the pericyclic cascade pathway (Pathway A, Scheme 1). The key steps common to these three pathways are laid out in Figure 13. The key step of the Fischer indole synthesis is an aromatic hetero-Claisen rearrangement $(3,4-$ diaza-Cope rearrangement, Fig 13a); this corresponds to a 3aza,4-oxa-Cope rearrangement involved in both pathways A and $\mathrm{B}$ in the present study (Fig 13b and c). Our previous work found that Fischer indolization substrates with certain substitution patterns, such as the one shown in Fig 13a, do not undergo the desired rearrangement. ${ }^{40}$ Instead, heterolysis of the $\mathrm{N}-\mathrm{N}^{(+)}$bond occurs, giving an aniline and a resonancestabilized carbocation. Our computations showed that these attempted rearrangements fail because the electron-donating groups on the terminal aliphatic carbon of the rearranging system significantly lower the bond dissociation enthalpy of the $\mathrm{N}-\mathrm{N}^{(+)}$bond, and favor the heterolysis of this bond over the intended [3,3]-sigmatropic rearrangement. Similarly, 3-aza,4oxa-Cope rearrangement transition states of pathways A and B contain a disubstituted alkylidene group derived from the ketene reactant (Fig $13 \mathrm{~b}$ and 13c). In accord with the previous findings, ${ }^{40}$ the located transition structures, TS-[3,3] and TS'$[3,3]$ are both early and highly asynchronous, indicative of significant weakening of the $\mathrm{O}-\mathrm{N}$ bond (Fig 12). Our calculations predict that $\mathbf{T S}-[\mathbf{3 , 3}]$ in pathway A gives the rearranged product (Fig 13c), but the analogous TS'-[3,3] in pathway $\mathrm{B}$ leads to heterolysis of the $\mathrm{O}-\mathrm{N}^{(+)}$bond akin to the heterolytic cleavage of the $\mathrm{N}-\mathrm{N}^{(+)}$bond in the Fischer indole reaction (Fig 13b). The formation of the non-charge separated arylimine and $\alpha$-lactone products $(\Delta G=-40.5 \mathrm{kcal} / \mathrm{mol})$ favors heterolysis over rearrangement in pathway B. On the other hand, the ketene oxygen is involved in the hemiaminal linkage in the cycloadduct making the rearranging system in pathway A uncharged. With no formal positive charge on nitrogen, the subsequent [3,3]-shift proceeds via TS-[3,3] in a concerted manner. This rearrangement is facile, presumably driven by both the electronic effects that weaken the N-O bond and the release of the ring strain. Thus, the competing high-energybarrier to heterolysis of the $\mathrm{O}-\mathrm{N}^{+}$bond disfavors the operation of the nucleophilic addition-hetero-Claisen pathway. By contrast, our proposed pathway proceeds first by a $3+2$ cycloaddition, yielding an uncharged system, which can undergo facile [3,3]-rearrangement. Comparison of pathway $\mathrm{B}$ (Fig 13b) and the case of a failed Fischer indolization attempt (Fig 13a) suggests the importance of electronic effects in hetero-Claisen rearrangements.
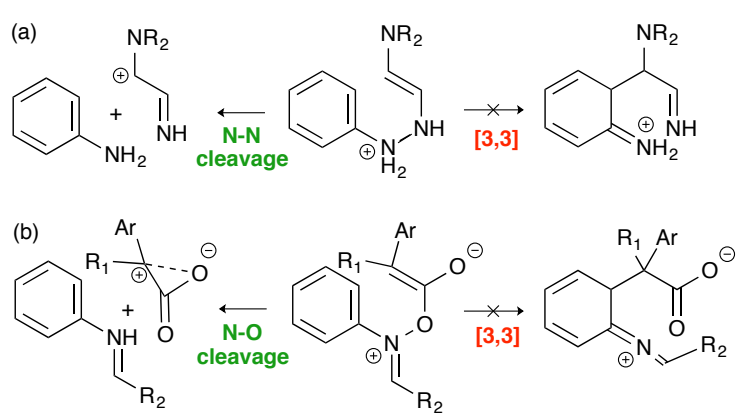

(c)

Fig. 13. Competing [3,3]-rearrangement and cleavage pathways (a) in the Fischer indole synthesis; ${ }^{39}$ (b) in pathway $B$; (c) in pathway $A$.

\section{Attempted Intermediate Isolation}

Experimental validation of the computationally predicted cycloaddition pathway by trapping anticipated reaction intermediates was probed. Initially, in an attempt to preclude the proposed rearomatization step, $N$-xylyl nitrone $\mathbf{5 4}$ was prepared and treated with an equivalent of ethylphenylketene. However, rather than the expected seven-membered intermediate, dearomatized imino-lactone $\mathbf{5 5}$ was produced as a 3.5:1 mixture of diastereoisomers. The major diastereoisomer was isolated in $66 \%$ yield after crystallization from $\mathrm{MeOH}$, with the relative configuration within $\mathbf{5 5}$ proven by X-ray crystallography. ${ }^{41}$
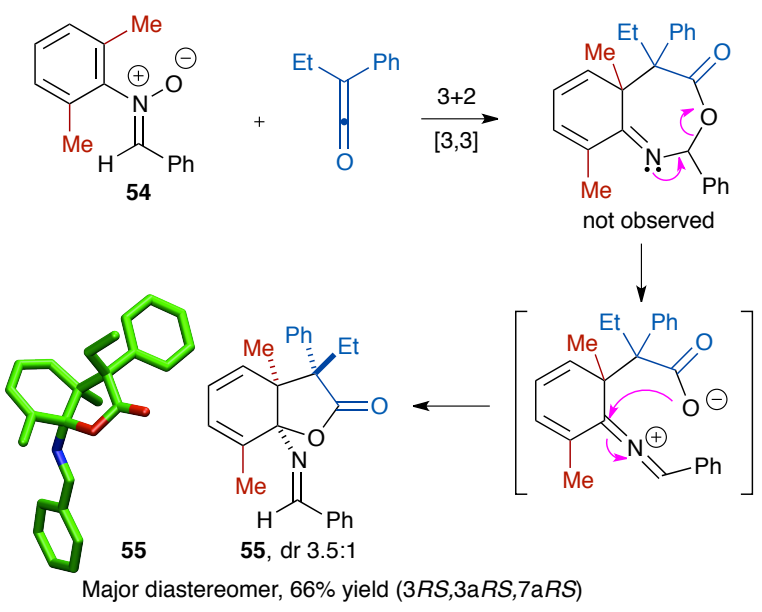

Scheme 2. Formation of lactone 55.

Next, replacement of the nitrone $N$-aryl substituent with a saturated alkyl substituent, thereby removing the potential for $[3,3]$-sigmatropic rearrangement was investigated. Treatment of $\mathrm{N}$-tert-butyl nitrone $\mathbf{5 6}$ with an equivalent of ethyl(parachlorophenyl)ketene $\mathbf{5 7}$ gave oxazolidinone $\mathbf{5 9}$ in 3:1 crude dr (Scheme 3). The major diastereoisomer was isolated in $41 \%$ yield with $\mathrm{N}$-tert-butyl imine also formed in this reaction. ${ }^{42}$ Isolation of $\mathbf{5 9}$ provides indirect evidence for the computed 
reaction mechanism via initial $3+2$ cycloaddition across the ketene $\mathrm{C}=\mathrm{O}$ bond to furnish transient intermediate $\mathbf{5 8}$ which, via radical or ionic cleavage of the $\mathrm{N}-\mathrm{O}$ bond, rearranges to generate the 5-membered oxazolidinone 59. ${ }^{43}$ An alternative dissociative decomposition of intermediate $\mathbf{5 8}$ can be envisaged to account for the generation of $N$-tert-butyl benzaldehyde imine 60 via $\mathrm{N}-\mathrm{O}$ bond cleavage without concomitant $\mathrm{C}-\mathrm{C}$ bond formation, resulting in elimination of the parent arylbutyric acid $\mathbf{6 1}$.<smiles>CCC(=C=O)c1ccc(Cl)cc1</smiles>

56 57<smiles>CCC(Br)=C1OC(c2ccccc2)C(C)(c2ccccc2)N1C(C)(C)C</smiles><smiles>CCC(C(=O)O)c1ccc(Cl)cc1</smiles><smiles>CC(C)(C)N=Cc1ccccc1</smiles>

Scheme 3. Isolation of oxazolidinone $\mathbf{5 9}$ 58

$59,41 \%, 3: 1 d r$

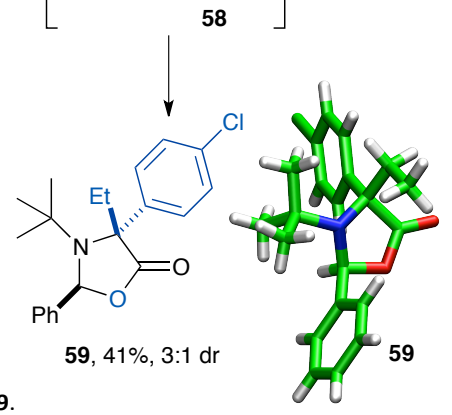

Application to a Target Compound: Anti-Cancer Agent

Finally, to demonstrate the efficiency of this pericyclic methodology and its potential utility in synthesis, Roche p53 inhibitor $^{44}$ (RO4999200) 1 was selected as a target, with ent-1 synthesized in three simple steps from commercially available starting materials. ${ }^{45}$ Recently, Kündig and co-workers reported the first asymmetric approach toward this species based upon a palladium-catalyzed intramolecular $\alpha$-arylation, ${ }^{46}$ while the Roche route relies upon chiral HPLC separation. ${ }^{47}$ Feng and coworkers also recently reported an expedient catalytic preparation of $1 .^{48}$ Our synthesis began with alkylation of commercially available $m$-anisylacetic acid $\mathbf{6 2}$, followed by conversion to the acid chloride $\mathbf{6 3}$, which was isolated in $87 \%$ yield over two steps. Dehydrohalogenation provided ketene 64, which was used without isolation as a crude solution in THF (Scheme 4). In congruence with our previous regioselectivity studies, treatment of the $N$-3-chlorophenyl $N$ '-TIPBS nitrone 48 with 64 provided a 60:40 mixture of 6- and 4-regioisomeric oxindoles, which could be readily separated by column chromatography over silica. Roche p53 inhibitor ent-1 was isolated in 52\% yield and $96 \%$ ee, whilst the novel regioisomer $\mathbf{6 5}$ was isolated in $36 \%$ yield and $79 \%$ ee.

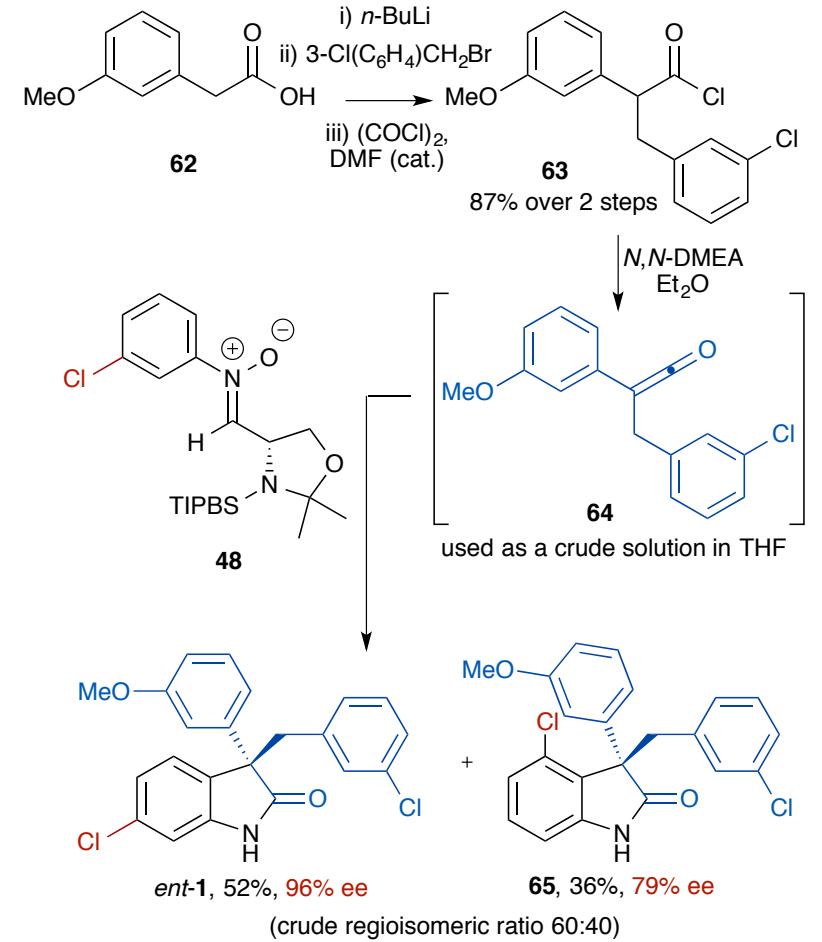

Scheme 4. Application of this methodology to the synthesis of Roche anti-cancer agent ent-1, and novel analogue 65 .

\section{Conclusions}

In summary, the optimization of the asymmetric heteroClaisen approach to oxindoles has been demonstrated. By variation of the chiral nitrone structure, $N$-TIPBS nitrone 20 was identified as an excellent transmitter of chiral information in reaction with a variety of alkylarylketenes ( $>15$ examples). A range of substituted aryl $N$-TIPBS nitrones was also prepared and used in a survey of the regioselectivity of this transformation (8 examples). These synthetic studies are consistent with the previous computational examination of this reaction system, and the proposed pericyclic cascade mechanism accounts for the observed levels of enantioselectivity.

Further computational investigation revealed that the traditionally invoked mechanistic rationale for this process is energetically improbable under the reaction conditions, and instead results in a dissociative, non-productive fragmentation event. In contrast, the proposed $3+2,[3,3]$-cascade mechanism is found to be a facile, energetically downhill process, and is substantiated by the isolation of oxazolidinone 59. As a demonstration of synthetic utility, this methodology was used in a concise, asymmetric preparation of Roche p53 inhibitor ent-1 in $96 \%$ ee, along with novel regioisomer 65. Current efforts within our laboratory are focused on application of this asymmetric methodology in complex molecule synthesis.

\section{Acknowledgements}


We thank the Royal Society for a URF (ADS), Cancer Research UK (ER), the Leverhulme Trust (ND) and EPSRC (KBL) for funding. We are also grateful to the National Science Foundation (USA) for financial support of the research at UCLA (KNH). We thank J. Douglas and S. M. Leckie for preparation of previously reported ketenes and Andrew Thomas (Roche) for data related to oxindole 1. We also thank the EPSRC National Mass Spectrometry Service Centre (Swansea).

We also thank the UCLA Institute for Digital Research and Education (IDRE), the XSEDE resources provided by the XSEDE Science Gateways Program (TG-CHE040013N) of the National Science Foundation (USA), and TUBITAK ULAKBIM High Performance and Grid Computing Center (TRUBA, Turkey) for generous computer time.

\section{Notes and references}

${ }^{a}$ EaStCHEM, School of Chemistry, University of St Andrews, North Haugh, St Andrews, KY16 9ST, UK. E-mail: ads10@st-andrews.ac.uk

${ }^{b}$ Department of Chemistry and Biochemistry, University of California, Los Angeles, 607 Charles E. Young Drive East, Los Angeles, CA 90095, USA.E-mail: houk@chem.ucla.edu

${ }^{c}$ Department of Chemical Engineering, Yeditepe University, Istanbul, 34755, Turkey.

$\dagger$ Electronic Supplementary Information (ESI) available: all spectroscopic data and procedures for novel compounds, computational methodology, comparision of B3LYP and MP2 geometries, full analysis of enantiomeric distributions, B3LYP-D geometries and energies, distortion-interaction analysis, the Cartesian coordinates of optimized structures, and the absolute energies and computed corrections of the reported geometries. See DOI: 10.1039/b000000x/

1. a) K. C. Nicolaou, D. J. Edmonds and P. G. Bulger, Angew. Chem., Int. Ed., 2006, 45, 7134-7186 and references therein; b) K. C. Nicolaou and J. S. Chen, Chem. Soc. Rev., 2009, 38, 2993-3009; c) A. Padwa, Chem. Soc. Rev., 2009, 38, 3072-3081; c) B. B. Toure and D. G. Hall, Chem. Rev., 2009, 109, 4439-4486; d) E. A. Anderson, Org. Biomol. Chem., 2011, 9, 3997-4006.

2. a) K. N. Houk, J. Gonzalez and Y. Li, Acc. Chem. Res., 1995, 28, 8190; b) P. H.-Y. Cheong, C. Legault, J. M. Um, N. Çelebi-Ölçüm and K. N. Houk, Chem. Rev., 2011, 111, 5042-5137. For a related pericyclic cascade approach to this manuscript that utilizes a nitrone [3+2] cycloaddition followed by 3,3 sigmatropic rearrangement see D-L. Mo, D. J. Wink and L. L. Andersen, Chem. E. J., 2014, 20, 13217-13225.

3. a) G. I. Elliott, J. Velicky, H. Ishikawa, Y. Li and D. L. Boger, Angew. Chem., Int. Ed., 2006, 45, 620-622; b) J. Poulin, C. M. Grise-Bard and L. Barriault, Chem. Soc. Rev., 2009, 38, 3092-3101.

4. For reviews, see: a) C. Marti, and E. M. Carreira, Eur. J. Org. Chem., 2003, 2209-2219; b) C. V. Galliford, and K. A. Scheidt, Angew. Chem., Int. Ed., 2007, 46, 8748-8758.

5. M. K. Christensen, K. D. Erichsen, C. Trojel-Hansen, J. Tjørnelund, S. J. Nielsen, K. Frydenvang, T. N. Johansen, B. Nielsen, M. Sehested,
P. B. Jensen, M. Ikaunieks, A. Zaichenko, E. Loza, I. Kalvinsh and F. Björkling, J. Med. Chem., 2010, 53, 7140-7145.

6. T. D. Bagul, G. Lakshmaiah, T. Kawabata and K. Fuji, Org. Lett., 2002, 4, 249-251.

7. a) L. E. Overman and Y. Shin, Org. Lett., 2007, 9, 339-341; b) J. E. DeLorbe, S. Y. Jabri, S. M. Mennen, L. E. Overman and F.-L. Zhang, J. Am. Chem. Soc., 2011, 133, 6549-6552.

8. J. Christoffers and A. Mann, Angew. Chem., Int. Ed., 2001, 40, 45914597.

9. a) B. M. Trost and M. K. Brennan, Synthesis, 2009, 3003-3025; b) F. Zhou, Y-L. Liu, J. Zhou, Adv. Synth. Catal., 2010, 352, 1381-1407; c) L. M. Repka and S. E. Reisman, J. Org. Chem., 2013, 78, 1231412320.

10. P. B. Alper, C. Meyers, D. R. Lerchner, D. R. Siegel and E. M. Carreira, Angew. Chem., Int. Ed., 1999, 38, 3186-3189.

11. S. Edmonson, S. J. Danishefsky, L. Sepp-Lorenzino and N. Rosen, J. Am. Chem. Soc., 1999, 121, 2147-2155.

12. R. He, C. Ding and K. Maruoka, Angew. Chem., Int. Ed., 2009, 48, 4559-4561.

13. a) S. Lee, and J. F. Hartwig, J. Org. Chem., 2001, 66, 3402-3415; b) J. E. M. N. Klein and R. J. K. Taylor, Eur. J. Org. Chem., 2011, 6821-6841.

14. A. B. Douney, K. Hatanaka, J. J. Kodanko, M. Oestreich, L. E. Overman, L. A. Pfeifer and M. M. Weiss, J. Am. Chem. Soc., 2003, 125, 6261-6271.

15. a) L. E. Overman and M. D. Rosen, Angew. Chem., Int. Ed., 2000, 39, 4596-4599; b) A. B. Douney and L. E. Overman, Chem. Rev., 2003, 103, 2945-2964.

16. a) P. E. Kündig and Y-X. Jia, Angew. Chem., Int. Ed., 2009, 48, 16361639; b) R. J. K. Taylor and A. Perry, Chem. Commun., 2009, 32493251 .

17. a) B. M. Trost and M. Osipov, Angew. Chem., Int. Ed., 2013, 52, 9176-9181; b) B. M. Trost and M. K. Brennan, Org. Lett., 2006, 8, 2027-2030.

18. I. D. Hills and G. C. Fu, Angew. Chem., Int. Ed., 2003, 42, 39213924.

19. G. S. Singh and Z. Y. Desta, Chem. Rev., 2012, 112, 6104-6155.

20. a) K. Zheng, C. Yin, X. Lin, L. Lin, and X. Feng, Angew. Chem. Int. Ed., 2011, 50, 2573-2577; b) B. Tan, G. Hernandez-Torres and C. F. Barbas, III, J. Am. Chem. Soc., 2011, 133, 12354-12357.

21. a) G. Lakshmaiah, T. Kawabata, M. Shang and K. Fuji, J. Org. Chem., 1999, 64, 1699-1704; b) S. Ma, X. Han, S. Krishnan, S. C. Virgil and B. M. Stoltz, Angew. Chem., Int. Ed., 2009, 48, 80378041 .

22. H. Staudinger and G. Miescher, Helv. Chim. Acta, 1919, 2, 554-582.

23. C. H. Hassall and A. E. Lippman, J. Chem. Soc., 1953, 1059-1063.

24. M. Hafiz and G. A. Taylor, J. Chem. Soc., Perkin Trans. 1, 1980, 8, 1700-1705.

25. N. Duguet, A. M. Z. Slawin and A. D. Smith, Org. Lett., 2009, 11, 3858-3861.

26. E. Richmond, N. Duguet, A. M. Z. Slawin, T. Lebl and A. D. Smith, Org. Lett., 2012, 14, 2762-2765.

27. N. Çelebi-Ölçüm, Y.-h. Lam, E. Richmond, K. B. Ling, A. D. Smith, and K. N. Houk, Angew. Chem., Int. Ed., 2011, 50, 11478-11482.

28. R. W. Hoffmann, Chem. Rev. 1989, 89, 1841-1860. 
29. In our previous studies (ref. 26), the corresponding aldehyde has been isolated from a crude reaction mixture and retreated with $\mathrm{PhNHOH}$ to regenerate TIPBS nitrone 20. The nitrone has then been shown to be an effective chiral auxiliary in a second cycle of asymmetric oxindole synthesis.

30. A brief solvent and temperature screen was undertaken (see SI for details). The use of THF as solvent at a reaction temperature of -78 ${ }^{\circ} \mathrm{C}$ remained optimal for both yield and enantioselectivity of the product oxindole.

31. The obtained silyl-nitrones were found to hydrolyze on attempted purification by column chromatography, and were not amenable to storage. Consequently, these nitrones were prepared and used immediately as crude residues and only limited characterization data was obtained. Their instability, however, rendered them impractical as potential nitrone chiral auxiliaries.

32. CCDC 1029035 contains the supplementary crystallographic data for 20. These data can be obtained free of charge from the Cambridge Crystallographic Data Centre via www.ccdc.cam.ac.uk/data_request/cif.

33. M. J. Frisch et al. Gaussian 09, revision A.2, Gaussian, Inc., Wallingford, CT, 2009. See SI for the full citation.

34. H. R. Seikaly and T. T. Tidwell, Tetrahedron, 1986, 42, 2587-2613.

35. C. E. Cannizzaro, T. Strassner and K. N. Houk, J. Am. Chem. Soc., 2001, 123, 2668-2669.

36. $\pi-\pi$ interactions displayed in the X-ray structure of nitrone $\mathbf{2 0}$ suggest the importance of dispersion interactions in determining the selectivity at the cycloaddition step. Optimizations using dispersion corrected density functional theory gave similar geometries and relative energies; the results of calculations at the B3LYP-D3/6$311+\mathrm{G}(\mathrm{d}, \mathrm{p}) / / \mathrm{B} 3 \mathrm{LYP}-\mathrm{D} / 6-31 \mathrm{G}(\mathrm{d})$ level are given in the SI.

37. For all reactions described herein, racemic oxindole samples were obtained from reaction of the requisite achiral diarylnitrone and alkylarylketene (see SI for experimental details). For the enantioenriched oxindoles, the absolute configuration is assigned by analogy to that determined by derivatization in our earlier publication (ref. 25).

38. J. E. DeLorbe, D. Horne, R. Jove, S. M. Mennen, S. Nam, F-L. Zhang and L. E. Overman, J. Am. Chem. Soc., 2013, 135, 4117-4128.

39. After fourteen days, an ee value of $30 \%$ was obtained when the HPLC sample of oxindole 37 was reanalyzed.

40. N. Çelebi-Ölçüm, B. W. Boal, A. D. Huters, N. K. Garg and K. N. Houk, J. Am. Chem. Soc., 2011, 133, 5752-5755.

41. Stokes and Taylor have described the isolation of a very similar lactone species using the same xylylnitrone starting material: D. P. Stokes and G. A. Taylor, J. Chem. Soc. C, 1971, 2334-2336. The relative configuration within $\mathbf{5 5}$ was confirmed by single crystal Xray diffraction. CCDC 1029036 contains the supplementary crystallographic data for 55. These data can be obtained free of charge from the Cambridge Crystallographic Data Centre via www.ccdc.cam.ac.uk/data_request/cif.

42. The relative configuration within $\mathbf{5 9}$ was confirmed by single crystal X-ray diffraction. CCDC 1029037 contains the supplementary crystallographic data for 59. These data can be obtained free of charge from the Cambridge Crystallographic Data Centre via www.ccdc.cam.ac.uk/data_request/cif.
43. The generation of oxazolidinones in reactions of symmetric ketenes and nitrones has been previously observed and investigated; for selected examples see R. N. Pratt, D. P. Stokes and G. A. Taylor, J. Chem. Soc., Perkin Trans. 1, 1975, 498-503; M. A. Abou-Gharbia and M. M. Jouillie, J. Org. Chem., 1979, 44, 2961-2966. Through an ${ }^{17} \mathrm{O}$ labeling study, Evans and Taylor provided experimental evidence for the proposed $3+2$ cycloaddition/1,3 rearrangement pathway for the formation of oxazolidinones from diarylnitrones and ketenes. The possibility of $\alpha$-lactone formation in this transformation via oxygen atom transfer to ketenes was also probed. However, a subsequent competing deoxygenation-recombination mechanism involving the addition of $\alpha$-lactones to nitriles and imines was concluded to be an unlikely mechanistic pathway for this transformation. For further details see: A. R. Evans and G. A. Taylor, J. Chem. Soc. Perkin Trans. 1, 1987, 567-569.

44. p53 is a tumour suppressor protein that is lost or suppressed in the majority of cancer cells. Inhibition of p53 has been shown to have two main therapeutic applications; in sensitizing cancer cells to other forms of chemotherapy and in protecting healthy non-cancerous cells from side effects associated with chemotherapy. For further details, see: A. V. Gudkov and E. A. Komarova, Biochem. Bioph. Res. Commun., 2005, 331, 726-736.

45. Using our L-serine derived chiral nitrone, the furnished oxindole is the enantiomer of the reported Roche compound. The absolute configuration of $\mathbf{B}$ prepared in this manuscript was assigned by HPLC analysis by analogy to reference 46 . Please see SI for further information.

46. D. Katayev and E. P. Kündig, Helv. Chim. Acta, 2012, 95, 2287-2295.

47. K. C. Luk, S. S. So, J. Zhang and Z. Zhang, F. Hoffmann-La Roche AG patent, 2006, WO2006/136606.

48. J. Guo, S. Dong, Y. Zhang, Y. Kuang, X. Liu, L. Lin, and X. Feng, Angew. Chem., Int. Ed., 2013, 52, 10245-10249. 